\title{
Physico-Mechanical, Morphological Properties of Polyvinyl Alcohol/Palm Kernel Shell/Coconut Kernel Shell Elastomeric Polymer Nanocomposites
}

\author{
Josephine Chang Hui Lai, ${ }^{*}$ and Nor Liyana Yusop \\ Department of Chemical Engineering, Universiti Malaysia Sarawak, Kota Samarahan, \\ Malaysia
}

\begin{abstract}
In this study, the physico-mechanical and morphological properties of polyvinyl alcohol/palm kernel shell/coconut kernel shell elastomeric polymer nanocomposites (PVA/PKS/CKS EPNCs) were investigated. PVA/PKS/CKS EPNCs were prepared via solution casting method and the properties of EPNCs were characterized through Fourier transform infrared (FTIR) spectroscopy, scanning electron microscopy (SEM), tensile testing and moisture absorption test. Test results showed that increasing the PVA content increased the tensile strength properties of EPNCs as well as provided smooth with no porous surface morphology. However, beyond certain percentage of PVA content, the moisture absorption increased too. Therefore, 55wt\% of PVA/PKS/CKS EPNCs was chosen as the best EPNCs as it had the best overall properties from the aspect of physico-mechanical, morphological and moisture absorption.
\end{abstract}

Keywords: Elastomeric polymer nanocomposites (EPNCs), polyvinyl alcohol, palm kernel shell, coconut kernel shell.

\section{Introduction}

Polymers matrix nanocomposites is defined as the combination of polymer matrix with at least one of the fillers are less $100 \mathrm{~nm}$ in dimension [1]. The benefits of polymer nanocomposites are that it can include the improvement in macroscopic properties of products compared to conventional composite [2].

An elastomer is a polymer that undergoes an immediate, linear and reversible response to high strain to an applied force which follows the Hooke's Law [3]. This class of polymer is used in the development of polymer-based nanocomposites to improve the properties. High-performance elastomeric nanocomposites have been produced by several research groups in the past with the incorporation of different types of inorganic fillers such as silica nanoparticles, layered silicates, carbon black, multi-walled carbon nanotubes and other nanomaterials [3].

EPNCs find applications in many sectors ranging from automobile tires and conveyor belts, hoses, adhesives, aircraft industry and others [4]. Thus, elastomer nanocomposite plays important role in interior structural usage.

Agricultural wastes such as palm kernel shell and coconut kernel shell are available abundantly in Malaysia. Palm kernel shell is one of the main by product of palm oil industry, which is generating about 4 million tons per annum in Malaysia [5]. Palm kernel shell is explored as one of the potential materials to be applied in polymer matrix to give major impact in mechanical properties as well as

\footnotetext{
* Corresponding author. Tel.: +6016-8957155; fax: +6082-583410

E-mail address: lchjosephine@ unimas.my

Manuscript History:

Received 17 September, 2018, Revised 24 September, 2018, Accepted 26 September, 2018, Published 30 September, 2018
}

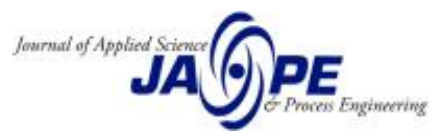


moisture absorption as palm kernel shell is lightweight, sustainable, environmentally friendly as well as low cost in obtaining raw material. Coconut kernel shells are available abundantly in Malaysia and all these wastes were disposed to the landfill. The huge amount of the coconut kernel shell wastes increased rapidly, and this leads to the huge disposal area and environmental pollution. Coconut kernel shell is rich in lignin, carbon content but low in ash content which provides high strength and hardness to the products [6]. Therefore, palm kernel shell and coconut kernel shell are selected for this research to enhance the tensile strength of the elastomeric polymer matrix.

There is very minimum work that has been reported on EPNCs using agricultural wastes, especially in combining two different types of agricultural wastes with elastomeric polymer to form nanocomposites. Therefore, the aim of this study was to synthesize polyvinyl alcohol/palm kernel shell/coconut kernel shell elastomeric polymer nanocomposites (PVA/PKS/CKS EPNCs) via solution casting method, and to investigate the effect of different ratios of PVA matrix on the physicmechanical, morphological and moisture absorption properties of PVA/PKS/CKS EPNCs.

\section{Experimental}

\subsection{Materials}

Palm kernel shell (PKS) and coconut kernel shell (CKS) were obtained from palm oil refinery in Kuching, Sarawak, Malaysia and coconut farm from Lundu, Sarawak, Malaysia. Both the agricultural wastes were obtained and grinded at the same time into powder form with dimension less than $30 \mathrm{~nm}$ by using the sieve analysis. The chemicals used to produce EPNCs were polyvinyl alcohol (PVA), which was supplied by Sigma Aldrich (St. Louis, USA).

\subsection{Preparation of PVA/PKS/CKS EPNCs using solution casting method}

Solution casting method was selected to fabricate EPNCs as this method ensured the well dispersion of polymer matrix into fillers. $10 \mathrm{wt} \%$ aqueous solution of polyvinyl alcohol (PVA) was continuously stirred at $90^{\circ} \mathrm{C}$ for 4 hours to avoid clumps. Palm kernel shell and coconut kernel shell powder is introduced into the polymer matrix according to the suggested ratio in Table 1 . The experimental conditions as listed in Table 1 were selected based on the optimum conditions from previous researchers [7-9]. The solutions were then poured into a mold and dried at $40^{\circ} \mathrm{C}$ for 1 days before being demoulded.

Table 1. Suggested ratio of the materials

\begin{tabular}{|c|c|c|}
\hline $\begin{array}{c}\text { Polyvinyl Alcohol } \\
\text { Matrices (wt\%) }\end{array}$ & $\begin{array}{c}\text { Palm Kernel Shell } \\
\text { Powder (wt\%) }\end{array}$ & $\begin{array}{c}\text { Coconut Kernel } \\
\text { Shell Powder (wt\%) }\end{array}$ \\
\hline 60 & 20.0 & 20.0 \\
\hline 55 & 21.5 & 21.5 \\
\hline 50 & 25.0 & 25.0 \\
\hline 45 & 27.5 & 27.5 \\
\hline 40 & 30.0 & 30.0 \\
\hline
\end{tabular}




\subsection{Characterization of PVA/PKS/CKS EPNCs}

The testing and analysis involved in this study are tensile test, Fourier Transform Infrared (FTIR) Spectroscopy, Scanning Electron Microscopy (SEM) and moisture absorption test. The surface chemistry was determined using Fourier transform infrared (FTIR) spectrophotometer (Model IRAffinity1). The standard method used was ASTM E168.

Scanning Electron Microscopy were used to perform morphological analysis on the EPNCs. The morphology of the samples was examined by using a scanning electron microscope (Hitachi TM3030). The test was carried out using ASTM E986-04(2017) standard. Before the SEM observation was done, the film was sputter-coated with a gold layer. This was to prevent electrostatic charging and to obtain high image resolution.

Tensile test was conducted to study the mechanical properties of the EPNCs. Autograph AGS-X Universal Tester (Shimadzu, Japan) were used to perform tensile test according to ASTM D882 standard. Cross-head speed was set at $50 \mathrm{~mm} / \mathrm{min}$ and the initial grip separation was set at $50 \mathrm{~mm}$. The tensile properties such as strain and stress are recorded for each set. Based on the data recorded, tensile strength could be calculated using formulas following Hooke's law.

Moisture absorption was carried out according to ASTM D57025 standard at room temperature. The samples were dried in an oven for 72 hours at $60^{\circ} \mathrm{C}$. The sample was then cooled in a desiccator, and immediately weighted.

\section{Results and Discussion}

\subsection{Fourier Transform Infrared (FTIR) Spectroscopy}

Fourier transform infrared spectroscopy was performed based on the suggested five ratios of samples. Figure 1 showed the FTIR spectra of the five samples of different ratios. The blue line represented 60wt\% PVA, the green line represented 55wt\% PVA, the grey line represented 50wt\% PVA, the red line represented 45wt\% PVA and the black line represented 40wt\% PVA.

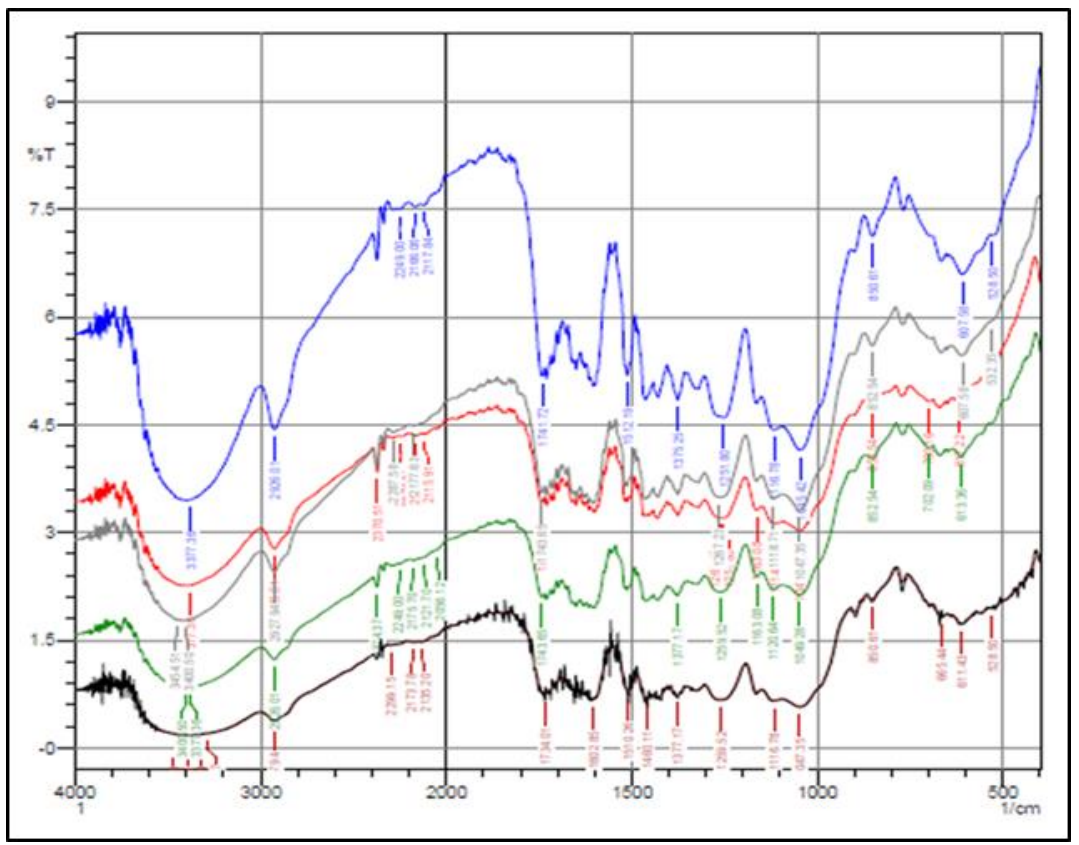

Figure 1: FTIR spectra of five samples with different ratios. 
From Figure 1, there was stretching transmittance appeared between $3600 \mathrm{~cm}^{-1}$ and $3100 \mathrm{~cm}^{-1}$ which was related to O-H transmittance. The stretching transmittance of $60 \mathrm{wt} \%$ PVA had the most intense stretching, followed by 50wt\% PVA, 45wt\% PVA, 40wt\% PVA and lastly 55wt\% PVA. Intense $\mathrm{O}-\mathrm{H}$ transmittance indicated that there was a presence of strong intermolecular and intramolecular hydrogen bonding [10]. This corresponded to the polyvinyl alcohol (PVOH) component. 60wt $\%$ of PVA had the strongest intermolecular and intramolecular hydrogen bonding that indicated $60 \mathrm{wt} \%$ PVA was the most likely to form hydrogen bonding with water. The miscibility between the polymer matrix and the fillers was due to the hydrogen bonding between PVA hydroxyl groups and carbonyl groups of fillers.

There were peaks appeared around $2942 \mathrm{~cm}^{-1}$ which corresponded to $\mathrm{C}-\mathrm{H}$ bond. The $\mathrm{C}-\mathrm{H}$ bond had weaker attraction compared to $\mathrm{O}-\mathrm{H}$ bond. The $\mathrm{C}-\mathrm{H}$ bond formed weaker attraction with moisture. $60 \mathrm{wt} \%$ PVA had the strongest $\mathrm{C}-\mathrm{H}$ bonding which indicated that $60 \mathrm{wt} \%$ of PVA was the most likely to interact with moisture.

Peaks in the range of $1200 \mathrm{~cm}^{-1}$ to $1000 \mathrm{~cm}^{-1}$ indicated the presence of methyl and methylene groups. These functional groups originated from palm kernel shell and coconut kernel shell that connected with another molecule through double bond. The double bond needed more energy to break compared to single bond which provided higher tensile strength for the EPNCs. Thus, 55wt\% PVA had the strongest double bonds based on Figure 1, due to the structural binder bonds of PVA with fillers at the optimum range.

Therefore, 55wt\% PVA/PKS/EKS EPNCs showed the optimum ratio to be fabricated compared to other ratios which enhanced the bonding intensity.

\subsection{Scanning Electron Microscopy (SEM)}

Five samples of EPNCs with different ratios were characterized on their surface morphology through scanning electron microscopy. Figure 2(a) to Figure 2(e) showed the surface morphology of five samples with different ratios. The combination of 55wt\% PVA matrix with PKS and CKS showed the best compatibility between matrix and fillers compared to other EPNCs. The surface morphology of $40 \mathrm{wt} \%$ PVA had the most pore and did not combine properly due to the brittle properties of palm kernel shell and coconut kernel shell [11]. Increasing the PVA matrix decreased the amount of the pores which led to better combination. This proved that the incorporation of PVA matrix into PKS and CKS fillers enhanced the compatibility [2]. However, 60wt\% PVA showed little cracking on the surface which proved that over introduction of PVA matrix decreased the compatibility towards the fillers. 

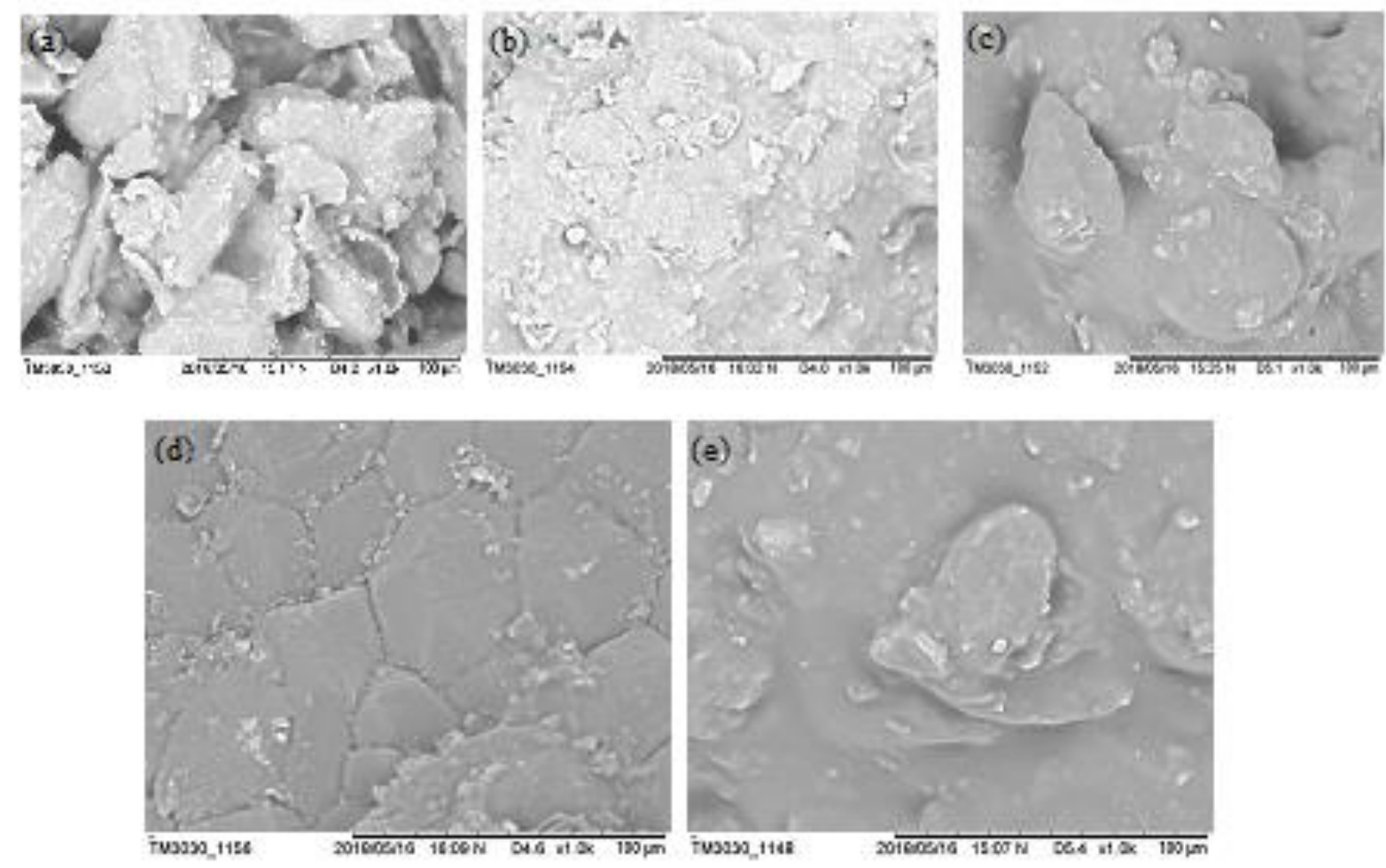

Figure 2: Surface morphology of (a) 40wt $\%$ PVA (b) $45 \mathrm{wt} \%$ PVA (c) $50 \mathrm{wt} \%$ PVA (d) $55 \mathrm{wt} \%$ PVA (e) $60 \mathrm{wt} \%$ PVA composites.

\subsection{Tensile Test}

Figure 3 showed the tensile test PVA/PKS/CKS EPNCs. Among all the nanocomposite systems, $55 \mathrm{wt} \% \mathrm{PVA} / \mathrm{PKS} / \mathrm{CKS}$ EPNCs showed the highest tensile strength when compared to other ratios of EPNCs. It showed that the tensile strength increased significantly when the appropriate amount of PVA matrix was added into the fillers to form EPNCs [2]. The elasticity came from the elastomeric properties of PVA matrix. Although PVA matrix was filled with two fillers, Figure 3 revealed a significantly higher decrease in tensile strength at $60 \mathrm{wt} \%$ due to the absence of any additional fibermatrix bonding mechanisms that caused lower dispersion which led to a higher drop in tensile strength at $60 \mathrm{wt} \%$ [12]. 


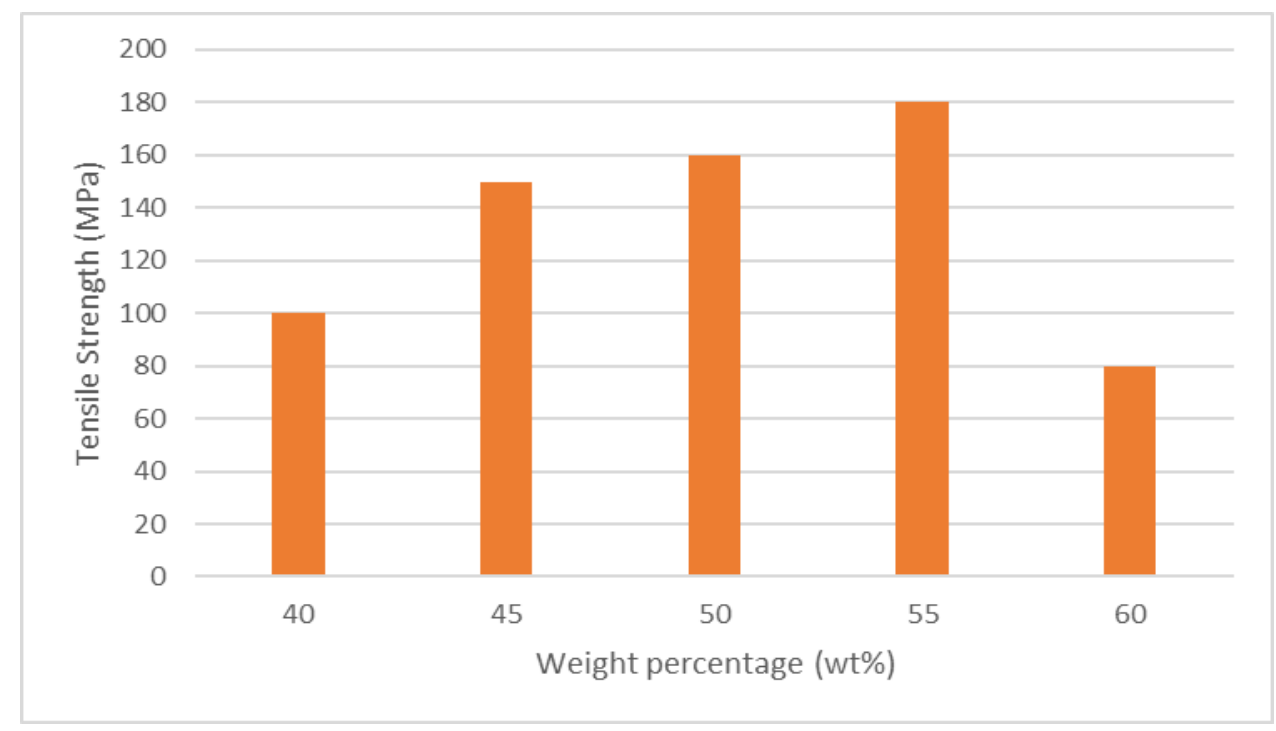

Figure 3: Tensile strength of (a) 40wt $\%$ PVA, (b) 45wt $\%$ PVA, (c) 50wt $\%$ PVA, (d) 55wt $\%$ PVA and (e) $60 \mathrm{wt} \%$ PVA composites.

\subsection{Moisture Absorption Test}

The moisture absorption characteristics of PVA/PKS/CKS EPNCs were presented in Figure 4. The moisture absorption increased until a certain saturation points at 100 minutes for PVA/PKS/CKS EPNCs. The amount absorbed was strongly dependent on the hydrophilic characteristics within the PVA matrix. The introduction of two fillers, namely PKS and CKS reduced the moisture absorption of the EPNCs due to the new chemical bonding formed between the matrix and fillers [13]. However, 60wt\% PVA matrix showed higher moisture absorption due to formation of hydrogen bonding between water molecules and the fibrous content of fillers [14-15]. Therefore, 55wt\% PVA/PKS/CKS EPNCs showed the lowest moisture absorption among all the nanocomposites.

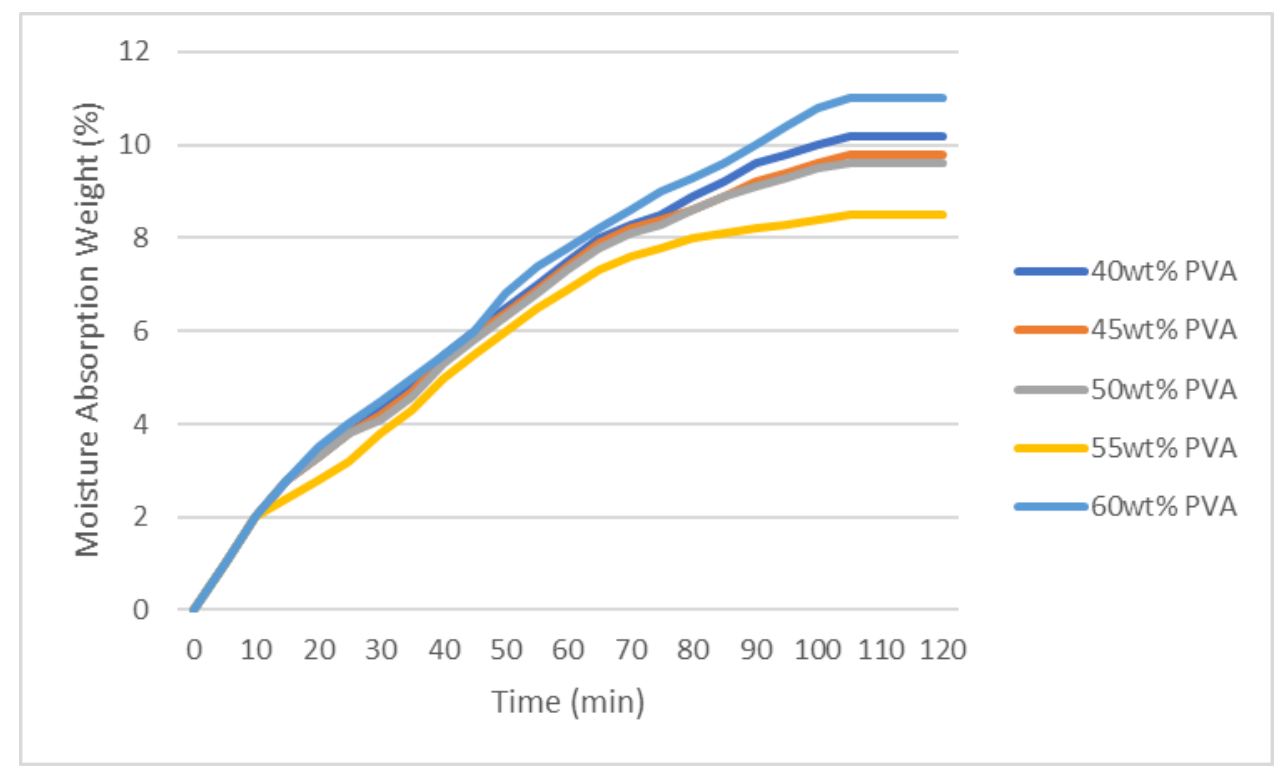

Figure 4: Moisture absorption weight of .PVA composites. 


\section{Conclusion}

PVA/PKS/CKS EPNCs were prepared by solution casting method and was successfully investigated the physico-mechanical, morphological and moisture absorption properties. Incorporation of PVA matrix at 55wt\% showed the best adhesion and compatibility with PKS and CKS fillers among all the nanocomposites. Based on the FTIR results, 55wt\% PVA matrix showed the least $\mathrm{OH}$ bonding compared to other ratios which proved that 55wt\% PVA/PKS/CKS EPNCs could formed strong bonding between matrix and fillers. In addition, 55wt\% PVA/PKS/CKS EPNCs showed the smoothest surface morphology with well compatibility of matrix and fillers compared to other ratios nanocomposites. Tensile strength of PVA/PKS/CKS EPNCs were significantly enhanced with the introduction of 55wt\% PVA matrix into PKS and CKS fillers, with clear proven from moisture absorption test.

\section{Acknowledgements}

The authors acknowledged the OSAKA Gas Foundation of International Cultural Exchange, for their financial support (Grant No. OSAKA Gas Grant Scheme 2017/2018) during this research.

\section{References}

[1] Lai, J. C. H., Rahman, M. R. and Hamdan, S. (2017). Physical, Mechanical, Morphological and Thermal Analysis of Styrene-Co-Glycidyl Methacrylate/Fumed Silica/Clay Nanocomposites. Jurnal Teknologi, Vol. 79, No. 5, 1-10.

[2] Lai, J. C. H., Rahman, M. R., Hamdan, S., Liew, F. K., Rahman, M. M. and Hossen, M. F. (2014). Impact of Nanoclay on Physicomechanical and Thermal Analysis of Polyvinyl Alcohol/Fumed Silica/Clay Nanocomposites. Journal of Applied Polymer Science, Vol. 132, No. 15, 41843(1-7).

[3] Shanks, R. A. and Kong, I. (2013). General Purpose Elastomers: Structure, Chemistry, Physics and Performance, Springer-Verlag Berlin Heidelberg.

[4] Khan, I., Usmani, M. A., Bhat, A. H., Rather, J. A., Hassan, S. I. and Muman. (2017). Recent Progress on Rubber Based Biocomposites: From Carbon Nanotubes to Ionic Liquids, Springer International Publishing AG.

[5] Itam, Z., Beddu, S., Mohd Kamal, N. L., Alam, M. A. and Ayash, U. I. (2016). The Feasibility of Palm Kernel Shell as a Replacement for Coarse Aggregate in Lightweight Concrete. International Conference on Advances in Renewable Energy and Technologies, Vol. 32, 1-5.

[6] Hidayu, A. R. and Muda, N. (2016). Preparation and Characterization of Impregnated Activated Carbon from Palm Kernel Shell and Coconut Shell for $\mathrm{CO}_{2}$ Capture. Procedia Engineering, Vol. 148, 106-113.

[7] King, P. J. (2013). Percolation effects in nanostructured thin films. Dublin: Trinity College Dublin.

[8] Abdullah, S. S. and Yusup, S. (2010). Method for screening of Malaysian biomass based on aggregated matrix for hydrogen production through gasification. Journal of Applied Science, Vol. 10, 3301-3306.

[9] Mphahlele, M. J., Maluleka, M. M., Rhyman, L., Ramasami, P. and Mampa, R. M. (2017). Spectroscopic, DFT, and XRD Studies of Hydrogen Bonds in N-Unsusbstituted 2-Aminobenzamides. Molecules, Vol. 27, No. 83, 1-14.

[10] Ong, H. L., Toh, G. Y., Nik Adik, N. N. A. and Abdullah, M. M. A. B. (2016). Utilization of Modified Palm Kernel Shell for Biocomposites Production. Key Engineering Materials, Vol. 700, 60-69.

[11] Alengaram, U. J., Jummat, Z. and Mahmud, H. (2008). Ductility Behavior of Reinforced Palm Kernel Shell Concrete Beams. European Journal of Scientific Research, Vol. 23, No. 3, 406-420.

[12] Majewski, L. Sikora, J. W. (2018). Mechanical Properties of Polyethylene Filled with Treated Neuburg Siliceous Earth. Technical Transactions, Vol. 8, 59-72. 
[13] Malakani, M., Bazyar, B., Talaiepour, M., Hemmasi, A. H. and Ghasemi, I. (2015). Effect of Acetylation of Wood Flour and MAPP Content During Compounding on Physical Properties, Decay Resistance, Contact Angle and Morphology of Polypropylene/Wood Flour Composites. BioResources, Vol. 2, No. 2, 2113 2129.

[13] Arib, R. M. N., Sapuan, S. M., Ahmad, M. M. H. M., Paridah M. T. and Khairul Zaman H. M. D. (2004). Mechanical Properties of Pineapple Leaf Fiber Reinforced Polypropylene Composites. Materials and Design, Vol. 27, 391-396.

[14] Acha, B. A., Marcovich N. E. and Reboredo, M. M. (2005). Physical and Mechanical Characterization of Jute Fabric Composites. Applied Polymer Science, Vol. 98, 639-650. 